\title{
The management of measurement processes - key to robust and cost optimal production of high quality products
}

\author{
R. Schmitt, J. Lose*, and M. Harding
}

Chair of Metrology and Quality Management, Laboratory for Machine Tools and Production Engineering, RWTH Aachen University, 52074 Aachen, Steinbachstr. 19, Germany

Received: 15 December 2009 / Accepted: 5 February 2010

\begin{abstract}
Today's production industry has to face considerable challenges. Decentralised and cross-linked production processes lead to a highly complex production control and a worldwide financial crisis causes drastic movements in demand. To succeed in business under these conditions, production needs to be transparent. One key factor to increase transparency is the management of measurement processes. The management of measurement processes focuses not only on the measurement process itself that enables the decision on the conformity of a measurand but, beyond that, it considers the acquisition of knowledge throughout the production process, its validation, processing and feedback into the process chain. With proof of measurement process capability, the determination of the optimal trade-off among measuring and production process, the adjustment of optimal working points and tolerances is achieved. The management of measurement processes allows obtaining a maximum benefit from metrology under the consideration of technical, organisational and economical boundary conditions.
\end{abstract}

Keywords: Management of measurement processes; transparency; validation; capability; tolerance design

\section{Introduction}

The importance of metrology as an enabling technology for high quality products and efficient processes is in considerable disparity to the perception of metrology in organizations. Metrological processes being the foundation for quality assurance activities are classified by controllers as supportive and are therefore not regarded as contributing to the value added stream. The conventional widespread premise that metrology is a "non-value-added necessary evil", must be viewed as obsolete thinking [1]. Therefore, the task is to rethink the term metrology as an enabling technology that adds value to the production process [2]. One way is to comprehend metrology as the key to knowledge.

\section{To measure is to know}

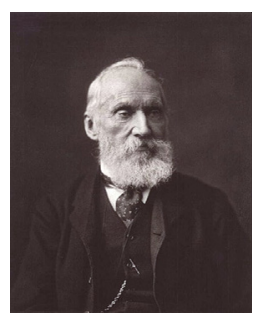

"I often say that when you can measure what you are speaking about, and express it in numbers, you know something about it; but when you cannot measure it, when you cannot express it in numbers, your knowledge is of a meagre and unsatisfactory kind"

Fig. 1. William Thomson, known as Lord Kelvin [3].

\footnotetext{
^ Correspondence: J.Lose@wzl.rwth-aachen.de
}

The statement of William Thomson, who is also known as Lord Kelvin, underlines that metrology generates knowledge (Fig. 1). In production, measurement processes generate knowledge to enable communication between the interacting technologies and/or humans related to the production system. Therefore, approaches of different disciplines like computer science [4], communication theory [5], linguistics [6] and economics [7] exist to specify the communication among these entities. But since the terms knowledge, information and data are used inconsistently it is essential to present an integrated definition connected to industrial production.

Figure 2 shows a definition that is based on the works of Aamodt and Nygård presented in [4]. A signal - the basis of the pyramid of knowledge - is any representation of information by a physical quantity that is generated by a signal source in order to transfer a message [8]. The signals consist of characters, i.e. elements of a specified amount of digital signals. The characters become data due to a defined syntax (principles and rules) [7]. The syntactic entities have no meaning themselves but are the input to an interpretation process. With the help of semantics, i.e. the study of meaning, data can be interpreted and therefore becomes information. Beyond that, knowledge results when information is integrated and is thus contextsensitive whereas information can be interpreted irrespective of the receiver of information [9]. According to [4] "knowledge is information incorporated in an agent's reasoning resources, and made ready for active use within a 


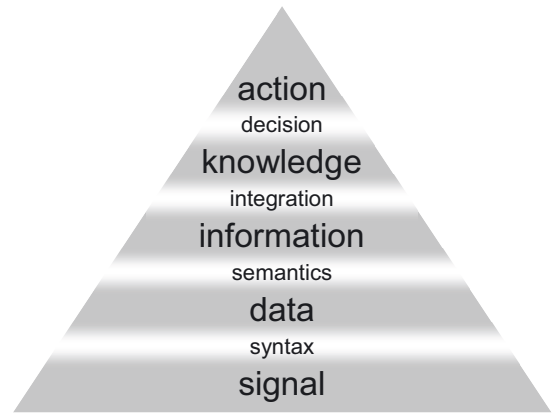

Fig. 2. Pyramid of knowledge (based on the definitional framework of [4]).

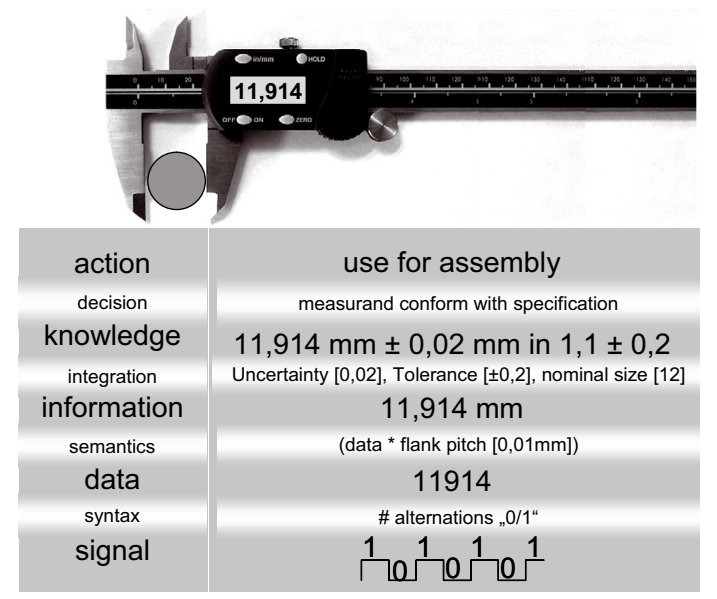

Fig. 3. Acquisition of knowledge by measurement.

decision process". Therefore, knowledge enables the agent to decide on actions.

In Figure 3, the example of a shaft diameter measurement with a digital calliper shows how metrology generates knowledge. The signal generated by the binary character stock $[0,1]$ of digital calliper's material measure. The signal alternates between 0 and 1 whenever the calliper exceeds a defined length, i.e. the flank pitch. The application of the syntax, a defined set of rules, transforms the signal to data. In this example the syntax is counting the number of alternations from 0 to 1 and vice versa which forms data "11914". The semantic connects the number "11914" with the specification of the calliper, the flank pitch, whereby the interpretable information $11,914 \mathrm{~mm}$ is formed. The integration of the information into the context with e.g. measurement uncertainty, nominal size and specified tolerance field transforms the information into knowledge. With the help of this knowledge it can be decided, that the measurand is in conformity with the specifications and can therefore be used for further manufacturing steps e.g. the assembly.

\section{Acquisition of knowledge in production}

The predominant comprehension of metrology is that the knowledge of measurement results enables decisions based on the conformity of a measurand. But to face the challenges of today's production industry with highly complex production systems and drastic movements in demand, production needs to be agile and therefore transparent. This means that the antiquated comprehension of quality assurance methods by measuring a product quality at the end of the production line needs to be replaced by the understanding that knowledge can be acquired throughout the entire production as indicated in Figure 4 - for example with inline and in-process metrology [10].

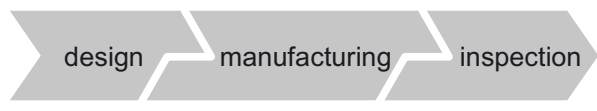

Fig. 4. Sources of knowledge in production.

In production, knowledge can be acquired in diverse ways through production metrology. The central task of production metrology is the acquisition of quality characteristics of a measurement object. The classic measurement object in production is the workpiece [11]. During and/or after manufacturing the specified inspection characteristics have to be checked. Thus, the inspection reduces the likeliness to deliver scrap to the next process step or even the customer.

Other objects of measurement can also be tools, machines or measurement devices and in order to provide robust production processes, it is relevant to expand the focus of knowledge acquisition on the entire manufacturing chain [11]. For instance, milling and turning are very common processes in industry today and process-monitoring by measurement of the tools is of crucial importance to optimise their productivity and minimise costs [12].

Another relevant focus is to ensure availability of the production machines. The reduction of downtimes is seen as a key to avoid severe consequences to the production process [13]. Downtime caused by technical failure is an important factor on the availability of manufacturing systems. A survey carried out by Volkswagen says that $80 \%$ of the downtime of a press in car body production is caused by technical failure [14]. One promising approach to increase the availability of the manufacturing systems is to measure and monitor the condition of critical or sensitive components of the manufacturing system with sensors. Damage can thus be detected before breakdown or even be avoided by preventive measures [13].

The overview of various sources of technically minable knowledge by means of metrology in production underlines that many knowledge sources offer a huge potential to take substantiated decisions and actions to stabilise and optimise production.

\section{Knowledge processing}

Since the sources and also the forms of appearance of knowledge are diverse, it needs to be processed to obtain a maximum benefit. Knowledge is integrated information and therefore context-sensitive and in particular 


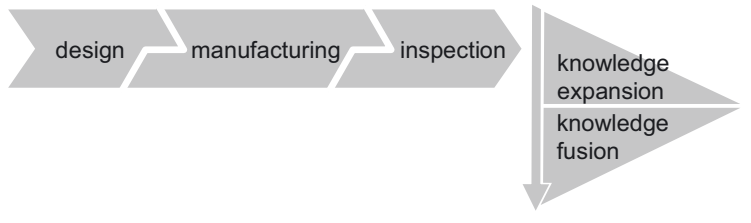

Fig. 5. Knowledge processing.

dependent on the receiver. Thus, it needs to be processed and forwarded in a comprehensible manner. In order to assure that all relevant information is forwarded to the receiver, the data format must offer all vital information uniformly. Particularly with regard to the increasing importance of continuous and online data acquisition, there is an increasing need for faultless, reliable data acquisition with little expenditure of time. For that reason, the data format AQDEF (Automotive Quality Data Exchange Format) was developed by a workgroup involving several major car manufacturers and suppliers such as BMW AG, Daimler AG, Volkswagen AG, GM Powertrain North America/Europe, Getrag Corporate Group, Ford-Werke $\mathrm{GmbH}$ and Robert Bosch $\mathrm{GmbH}$ and the software producer Q-DAS [15]. The quality data exchange format is characterised by its transparency (ASCII) and flexibility (editable). It is compressible, easy to copy (all information are saved in one data file) and transfer and language are independent by allocation of unique codes.

Dependent on the receiver and his background the knowledge needs to be processed appropriately so that the receiver gets a fast access, learns and can take decisions. As shown in Figure 5, knowledge can be processed by expansion, for instance temporally, and subsequent fusion, e.g. to key performance indicators, that make fast access to concentrated knowledge possible.

The most prominent examples of expanded and fused knowledge in production metrology are the indicators $c_{g}$ and $c_{P}$. The expansion takes place in time since temporally shifted measurement results are summarised and fused by variance calculation. The indicators provide concentrated information about the performance of measurement and production processes, provided that the receiver knows how to interpret the given values.

\section{Feedback of knowledge}

Whenever knowledge is acquired and processed, it is done with the purpose to pass it on to a receiver that can make use of it and is able to take decisions based on the gained knowledge. Figure 6 shows the backward chain that enables communication by a continuous feedback of knowledge to the various steps of production and can therefore generate benefit by diverse measures.

The acquired and processed knowledge can accordingly be applied to improve the single steps of entire chain of production processes, which then are source and receiver of knowledge at the same time. This feedback of knowledge is referred to as learning [4].

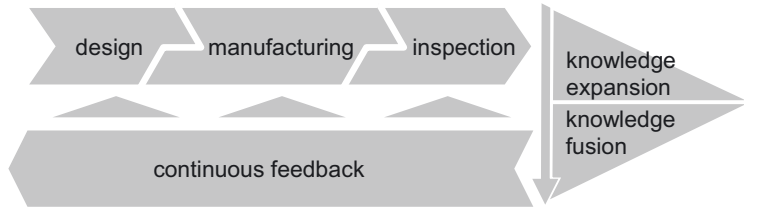

Fig. 6. Feedback of knowledge.

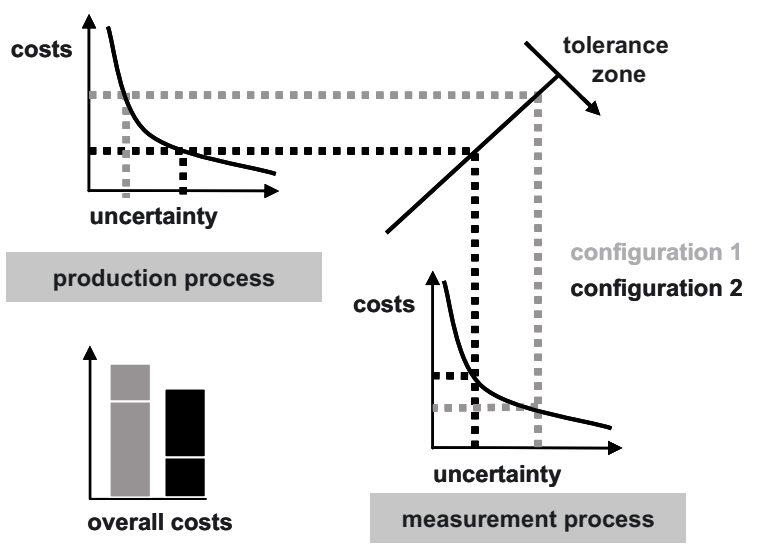

Fig. 7. Trade-off between production and measurement process.

Figure 7 demonstrates one potential to improve the production by minimizing costs with knowledge about the capabilities of measurement and production processes. The objective is to determine the optimal trade-off between production and measurement capabilities in order to guarantee the output quality at optimal costs. Both production and measurement process rise in costs when the uncertainties need to decrease.

It is both a claim and the potential of the management of measurement processes which can provide economic and capable measurement processes while utilising the residual tolerance zone for manufacturing.

Moreover, by utilising the knowledge about the capabilities of the production process the optimal working point can be set up in consideration of the objectives such as costs, quality or output. To do so, the uncertainty of measurement must be known since otherwise the observed cannot be assessed, as shown in Figure 8. For example, if the measurement device is uncertain but has a high display resolution, the observer may suppose that fluctuating values are due to fluctuations in manufacturing when in reality it is only due to the measurement system noise.

Furthermore, by knowledge of the capabilities of both production and measurement equipment, the design of tolerances can be critically and continuously analysed to provide for tolerances that can be met by the production and be measured as well. Anxiety-driven and non-producible tolerances that cause unreasonably high costs need to be discussed. Key performance indicators are a possibility to pass on knowledge in a condensed way with means such as the capability indices $c_{p} / c_{g}$ and $c_{p k} / c_{g k}$, SCP (statistical process control) or QFD (quality function deployment).

Another potential to improve production processes with the help of production metrology is the monitoring 


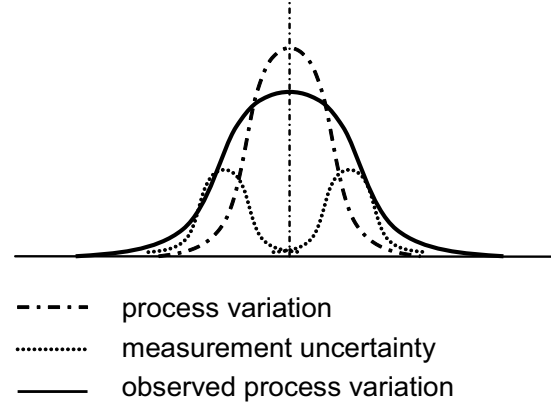

Fig. 8. Influence of measurement uncertainty on the observed process variation.

of the production machines' condition. Condition based maintenance allows minimizing the risk of down-times. In detail, condition based maintenance targets the following objectives [16]:

- Reducing downtimes caused by component wear out or failure.

- Reducing response times in cases of failures.

- Scheduling the efforts in maintenance to non-production times.

- Minimizing expenses in diagnoses due to online access.

- Optimizing spare parts management.

Generally, suitable metrological requirements for such a condition monitoring system are already met and available in the form of sensors in the production machine. The key to success is the consequent fusion of the acquired sensor data to compressed knowledge and its feedback into production. This enables rescheduling the production, planning the maintenance actions and ordering spare parts. Even if downtime cannot be avoided, a significant reduction of downtime is feasible [16].

\section{Knowledge validation}

Since decisions are taken on the basis of measurements, it is indispensable to validate the acquired knowledge. As mentioned before, the knowledge of the capability of the applied measuring devices bears the potential to improve the production process, for example by determining the optimal trade-off between measurement and production process or by tolerance management. But in order to do so, the measurement process must be capable of providing valid knowledge as it is the basis of every production control. This recognition led to a universal claim of proofs of measurement capability by the automotive industry and therefore constitutes the base procedures of the management of measurement processes, as shown in Figure 9. Accordingly, the features to be measured and the kind of measurement need to be chosen carefully and the capability must be proven.

It can easily be imagined that invalid knowledge, when processed and forwarded within the feedback chain to participating parties, may lead to erroneous decisions and actions. Whenever the acquired knowledge is forwarded not

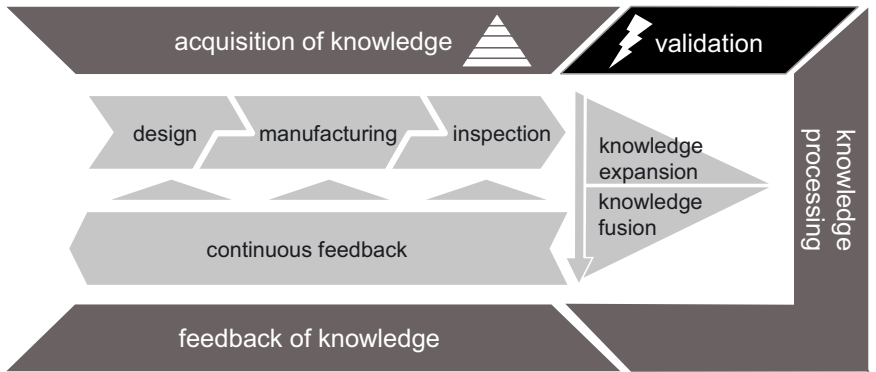

Fig. 9. Validation of knowledge as the basis of the management of measurement processes.

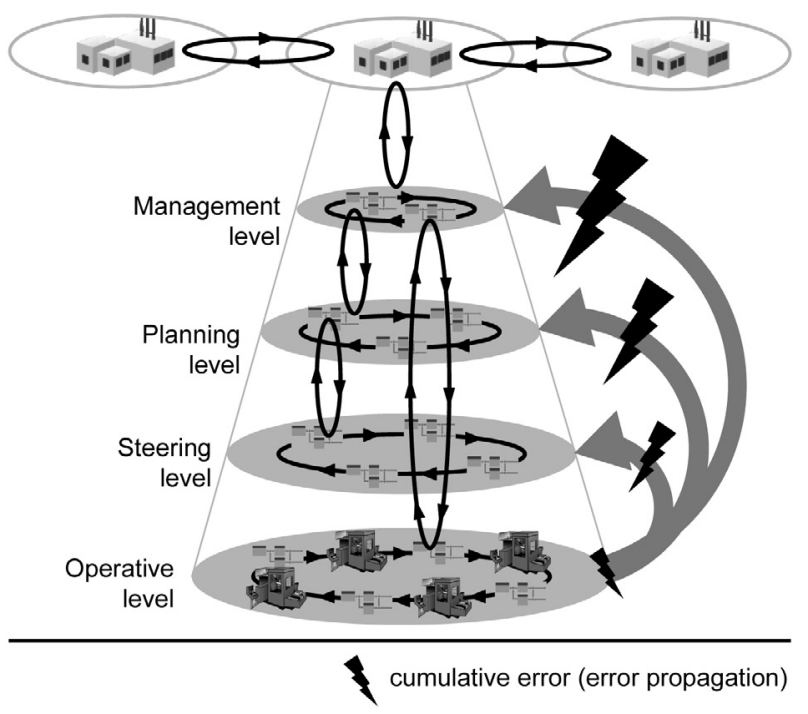

Fig. 10. Error propagation in organisations.

only within the operational level but also applied for decisions on higher levels, the error propagates and causes false decisions within the control loops of an organisation Figure 10. Incorrect decisions can only be reliably avoided when measurement processes are proven to be capable of the measurement task.

The expense for universal proofs of capability is immense. On the one hand, organisations have to deal with an enormous quantity of measurement processes and on the other the challenge is to prove the capability of complex measurement processes. According to [18], barely any other proceeding brought about so much expense than the proof of capability of measurement processes.

Indeed, several standards and directives specify procedures to prove the capability of measurement processes capability respectively uncertainty, such as the "Guide to the Expression of Uncertainty in Measurement" (GUM) [19], the Measurement System Analysis (MSA) [20] or the German directive VDA5 [21], to name just some of the most relevant. But the expenses to apply the procedures to every single measurement process are immense and the actual challenge is in the economic treatment of the masses of differing measurement processes within the organisations. 


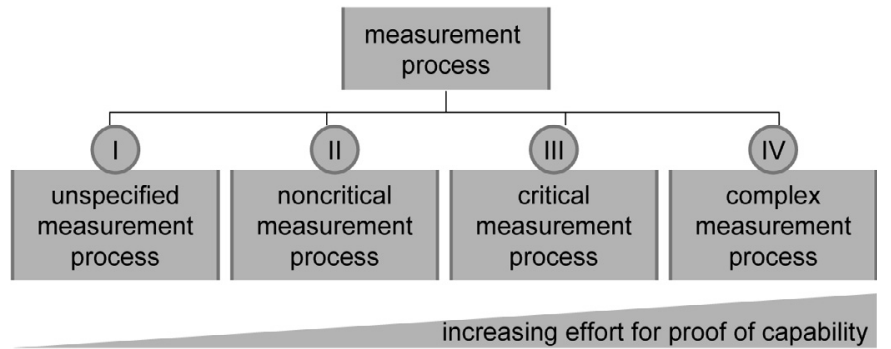

Fig. 11. Classification of measurement processes.

The classification of measurement processes is an approach that is to reduce the expenses for the proof of capability of measurement processes. The underlying principle is the assignment of measurement processes to classes based on their characteristics. The classes range from unspecified measurement process to complex measurement process (Fig. 11).

The measurement processes of the class "unspecified measurement process" are not assigned to a specified measurement task yet. For this reason, the minimum measurable tolerance of the measurement device can be estimated based on the MPE (maximum permissible error) according to [21]. An additional reduction of experimental proofs of capability can be achieved with the help of representative proofs of capability for the class of noncritical measurement processes, that are not security relevant and do not lead to significant follow-up costs. Only critical measurement processes and complex measurement processes need to be observed with individual proofs of capability. Critical measurement processes can be observed with the help of the standardised and simplified procedures of [20] and $[21]$.

A special challenge is the proof of capability of complex measurement processes since the procedures of [20] and [21] have a limited applicability. Different alternatives to the GUM [19] can be applied in this case: the execution of statistical experiments to set up a surrogate model of the uncertainties, the use of a calibrated masterpiece according to [22] or the application of the Monte Carlo method to an analytical model of the measurement process according to [23] to determine the uncertainties.

\section{Discussion}

Still, existing deficits within process control are the multitude of risks in the pre- and post area of the production processes which are usually not supervised. These factors can influence the produced quality significantly but their estimation is difficult. For example the changes in material properties among different batches are often difficult to measure. Additionally many optimisation measures of production processes are based on the experience of qualified personnel rather than measurements. Thus, changes in the production process may not be identified at all and the evaluation of the cause-effect-chain is compromised or not possible due to a lack of usable data [17]. For this reason, measures to represent and consider these factors within the management of measurement processes need to be developed.

However, the management of measurement processes offers various potentials to improve production with the help of knowledge acquisition of the already available and its validation, processing and feedback.

\section{Conclusion}

The management of measurement processes is a key factor to increase transparency in production. It focuses not only on the measurement process but also on the acquisition of knowledge throughout the production process, its validation, processing and feedback into the process chain. The use of knowledge allows obtaining a maximum benefit from metrology under the consideration of technical, organisational and economical boundary conditions. The validation of knowledge is a fundamental requirement to ensure that qualified decisions are taken thereupon.

Acknowledgements. The content described in this paper is based on the research and development project "ImProof ${ }^{K M U}$ ". This research and development project is funded by the German Federal Ministry of Education and Research (BMBF) and managed by the Project Management Agency Forschungszentrum Karlsruhe (PTKA).

\section{References}

1. B. Bunday et al., Value-Added Metrology, IEEE Trans. Semicond. Manuf. 20, 266 (2007)

2. H. Kunzmann, T. Pfeifer, R. Schmitt, H. Schwenke, A. Weckenmann, Productive Metrology - Adding Value to Manufacture, Ann. CIRP 54, 691 (2005)

3. W. Thomson, Electrical Units of Measurement, Popular Lecture an Addresses, Vol. I (Macmillan, London, 1883), p. 73

4. A. Aamodt, M. Nygård, Data Knowledge Eng. 16, 191 (1995)

5. C. Shannon, A Mathematical Theory of Communication, Bell Syst. Tech. J. 27, 379, 623 (1948)

6. F. de Saussure, Grundfragen der allgemeinen Sprachwissenschaft, 3rd edn. (De Gruyter, 2001)

7. K. North, Wissensorientierte Unternehmensführung Wertschöpfung durch Wissen, 2nd edn. (Gabler, 1999)

8. J.-R. Ohm, H. Lüke, Signalübertragung, 7th edn. (Springer, 2005)

9. A. Picot, R. Reichwald, R. Wigang, Die grenzenlose Unternehmung - Information, Organisation und Management, 5th edn. (Gabler, 2003)

10. R. Schmitt, B. Damm, P. Hafner, Machine-Vision-Based Automated Tool Wear Inspection System, in Proceedings of the 18th IMEKO TC2 Symposium (2008), pp. 1-6

11. T. Pfeifer, Production Metrology (2002), pp. 1-2

12. T. Pfeifer et al., Measuring flank tool wear on cutting tools with machine vision - a case solution, in 9th IEEE Conference on Mechatronics and Machine Vision in Practice (2002), pp. 169-175 
13. G. Schuh et al., Intelligent Maintenance - Potentiale zustandsorientierter Instandhaltung (2005), p. 6

14. H. Braeunlich, Blecheinzugsregelung beim Tiefziehen mit Niederhalter - ein Beitrag zur Erhöhung der Prozessstabilität (Verlag Wissenschaftliches Scripten, 2002), pp. 19-20

15. R. Ofen et al., Qualitätsdatenaustauschformat der Automobilindustrie AQDEF, workgroup paper version 2.0.1, http://www.q-das.de/fileadmin/files2/dataformat/ Specification_AQDEF_V3-0.pdf, 2008

16. G. Schuh et al., Designing services based on 'intelligent' press-die-systems, Advances in Life Cycle Engineering for Sustainable Manufacturing Businesses, in Proceedings of the 14th CIRP Conference on Life Cycle Engineering (2007), pp. 201-205

17. R. Schmitt et al., Anlage, Werkzeug, Betreiber Produktionseffizienz durch Anwenderorientierung, Wettbewerbsfaktor Produktionstechnik Aachener Perspektiven, in Proceedings of the AWK 2008, pp. 391-417
18. R. Brinkmann, Measurement System Analysis (MSA) und Prüfprozesseignung (Richtlinie VDA5), in VDI Berichte 1913 (VDI-Verlag, 2005), pp. 63-71

19. DINV ENV 13005, Guide to the Expression of Uncertainty in Measurement, German Version ENV 13005 (1999)

20. Measurement System Analysis (MSA), 3rd edn. (2002)

21. VDA 5 - Qualitätsmanagement in der Automobilindustrie, Prüfprozesseignung, 1st edn. (Verband der Automobilindustrie, 2003)

22. DIN ISO/TS15330-3, Geometrische Produktspezifikation (GPS) - Verfahren zur Ermittlung der Messunsicherheit von Koordinatenmessgeräten (KMG) - Teil 3: Anwendung von kalibrierten Werkstücken oder Normalen (2008)

23. JCGM 101:2008, Evaluation of measurement data Supplement 1 to the "Guide to the expression of uncertainty in measurement" - Propagation of distributions using a Monte Carlo method (2008) 